\title{
SILD synthesis of the efficient and stable electrocatalyst based on CoO-NiO solid solution toward hydrogen production
}

\author{
I. A. Kodintsev ${ }^{1}$, K. D. Martinson ${ }^{1}$, A. A. Lobinsky ${ }^{2}$, V. I. Popkov ${ }^{1}$ \\ ${ }^{1}$ Ioffe Institute, 194021 Saint Petersburg, Russia \\ ${ }^{2}$ Saint Petersburg State University, Peterhof, 198504 Saint Petersburg, Russia \\ i.a.kod@mail.ru
}

PACS 73.61.r, 81.15.z, 82.65.+r

DOI 10.17586/2220-8054-2019-10-6-681-685

\begin{abstract}
Currently, nanocrystalline $\mathrm{NiO}$ is well known as one of the best non-noble metal electrode material with low overpotential (OP) but mediocre stability. On the contrary, $\mathrm{CoO}$ has remarkable stability but the high values of OP. In this work, a method is proposed to achieve the stability of nickel oxide-based electrode materials while maintaining a low OP via the synthesis of a nanocrystalline CoO-NiO solid solution. Nanocrystals of $\mathrm{CoO}-\mathrm{NiO}$ solid solution were synthesized by successive ionic layer deposition (SILD). XRD, SEM, and EDX analysis show that the CoO$\mathrm{NiO}$ sample consists of $3-5 \mathrm{~nm}$ isometric crystallites of the solid solution mentioned above and $\mathrm{Ni} / \mathrm{Co}$ ratio is equal to $45.4 \% / 54.6 \%$ at. Electrochemical investigation of the nanocrystalline $\mathrm{CoO}-\mathrm{NiO}$ solution as electrode material shows OP values of $-240 \mathrm{mV}$ at a current density (CD) of $10 \mathrm{~mA} / \mathrm{cm}^{2}$, Tafel slope values of $78 \mathrm{mV} / \mathrm{dec}$ for hydrogen production from water-ethanol solution (10\% vol.) and high cyclic stability only $3 \mathrm{mV}$ degradation at $10 \mathrm{~mA} / \mathrm{cm}^{2}$ after 100 cycles of cyclic voltammetry. Thus, it was shown that the synthesis of a solid solution within the proposed approach makes it possible to maintain the high electrocatalytic properties inherent in $\mathrm{NiO}$, but with high stability in a wide range of overpotential and in the high cyclic load inherent in CoO.
\end{abstract}

Keywords: nickel oxide, cobalt oxide, successive ionic layer deposition, hydrogen evolution, electrocatalytic reforming.

Received: 25 July 2019

Revised: 25 November 2019

\section{Introduction}

The environmental pollution and growing energy crises have stimulated the development of clean electrochemical energy conversation and storage technologies $[1,2]$. Hydrogen has been regarded as one of the cleanest energy carriers for such purposes. Among the methods of hydrogen production is steam reforming [3, 4], biological processes [5], photoelectrolysis [6,7], water electrolysis [8,9] and electrochemical reforming [10,11]. The last one is the most interesting due to the clean and low-temperature process and the use of renewable organic sources (alcohols, carbohydrates, and others). Composites with $\mathrm{Pt}$, Ir and Ru exhibit the highest activity for hydrogen evolution reaction (HER), but it cannot be largely used in electrochemical reforming because of their rarity and high cost [12]. Therefore, durable, high-active and low-cost catalysts from transition elements have been attracted considerable attention since the last decade. These catalysts include sulfides $[13,14]$, phosphides $[15,16]$, nitrides $[17,18]$ and oxides $[19,20]$ of Mo, Co, $\mathrm{Fe}, \mathrm{V}, \mathrm{Ni}$ and other elements.

Nickel and cobalt oxides are typically used for hydrogen evolution reactions, but they are not ideal HER catalysts due to the low stability of $\mathrm{NiO}$ and high overpotential of $\mathrm{CoO}$ [21-23]. In this paper, we proposed a way to avoid the disadvantages of each oxide by synthesizing nanocrystals of $\mathrm{CoO}-\mathrm{NiO}$ solid solution by successive ionic layer deposition (SILD). The SILD method is one of the layer-by-layer synthesis methods based on successive and multiple treatments of the substrate in a salt solution that leads to the formation of insoluble nanolayers of the new compound upon interaction on the surface [24-26]. This method is suitable for the coating of most surfaces, even with irregular shapes and sizes, and it's allowed to precision control of multilayer thickness by changing the number of treatment cycles. The SILD method provides a simple and effective way for the creation of metal oxides composites for HER electrodes.

\section{Experimental}

Nickel plates with a size $5 \times 25 \mathrm{~mm}$ were used for electrochemical investigation, and monocrystalline silicon plates with the orientation of $\langle 100\rangle$ and a size $5 \times 20 \mathrm{~mm}$ were used for characterization by physicochemical methods. Before synthesis, both nickel and silicon plates were treated in acetone for 10 minutes into the ultrasonic bath. Then, nickel plates were treated for 15 minutes in aq. $6 \mathrm{M} \mathrm{HCl}$, then rinsed several times with deionized water and dried on the air at $80{ }^{\circ} \mathrm{C}$ for 30 minutes. Silicon plates were treated for 15 minutes in concentrated HF, for 20 minutes in diluted $\mathrm{KOH}$ solution with $\mathrm{pH}=9.0$, and finally were dried on the air at $80{ }^{\circ} \mathrm{C}$ for 30 minutes. 
$\mathrm{CoO}-\mathrm{NiO}$ solid solution was synthesized on the nickel and silicon plates by SILD method. As precursors were used the solution containing $0.01 \mathrm{M} \mathrm{Ni}\left(\mathrm{CH}_{3} \mathrm{COO}\right)_{2}$ and $0.01 \mathrm{M} \mathrm{Co}\left(\mathrm{CH}_{3} \mathrm{COO}\right)_{2}$ and the solution of $\mathrm{NaOH}$ with $\mathrm{pH}=9$. During the synthesis, the substrates were immersed for 30 seconds into the solution of $\mathrm{Ni}$ and Co salts, then into distilled water, $\mathrm{NaOH}$ solution, and distilled water again. Such treatment considered as one SILD cycle, which has been repeated several times. The synthesis of pure $\mathrm{CoO}$ and $\mathrm{NiO}$ samples was carried out according to the techniques previously described in the works $[23,24]$, so no additional physicochemical analysis was used to characterize synthesis products.

X-ray phase analysis was performed on a Rigaku SmartLab 3 X-ray powder diffractometer; phase analysis of the composition was performed using the ICDD PDF-2 powder database. The average crystallite size (coherent-scattering regions) was calculated from the broadening of X-ray diffraction lines using the Scherrer formula. Elemental analysis and morphology of the synthesized sample were studied by energy dispersive X-ray analysis (EDX) and scanning electron microscopy (SEM) using Tescan Vega 3 SBH scanning electron microscope equipped with an Oxford INCA $\mathrm{X}$-act X-ray microanalysis device.

Electrochemical properties of $\mathrm{CoO}-\mathrm{NiO}$ solid solution for electrochemical reforming were investigated using potentiostat Elins P-45X and a three-electrode cell. Nickel plate with nanocomposite film deposited via the layer-bylayer method was used as a working electrode, the $\mathrm{Ag} / \mathrm{AgCl}$ electrode was used as reference electrode and a platinum foil was used as a counter electrode. All measurements have been carried out at atmospheric pressure and room temperature in $1 \mathrm{M} \mathrm{KOH}$ solution with $10 \%$ (by volume) ethanol as the electrolyte. The voltammogram was made at a $5 \mathrm{mV} / \mathrm{s}$ sweep rate with IR compensation $(1.3 \Omega)$. The electrochemical stability of the electrode materials was characterized via standard cyclic voltammetry technique carried out for 100 cycles.

\section{Results and discussions}

Figure 1 shows the result of the XRD investigation of the CoO-NiO sample obtained by the SILD method.

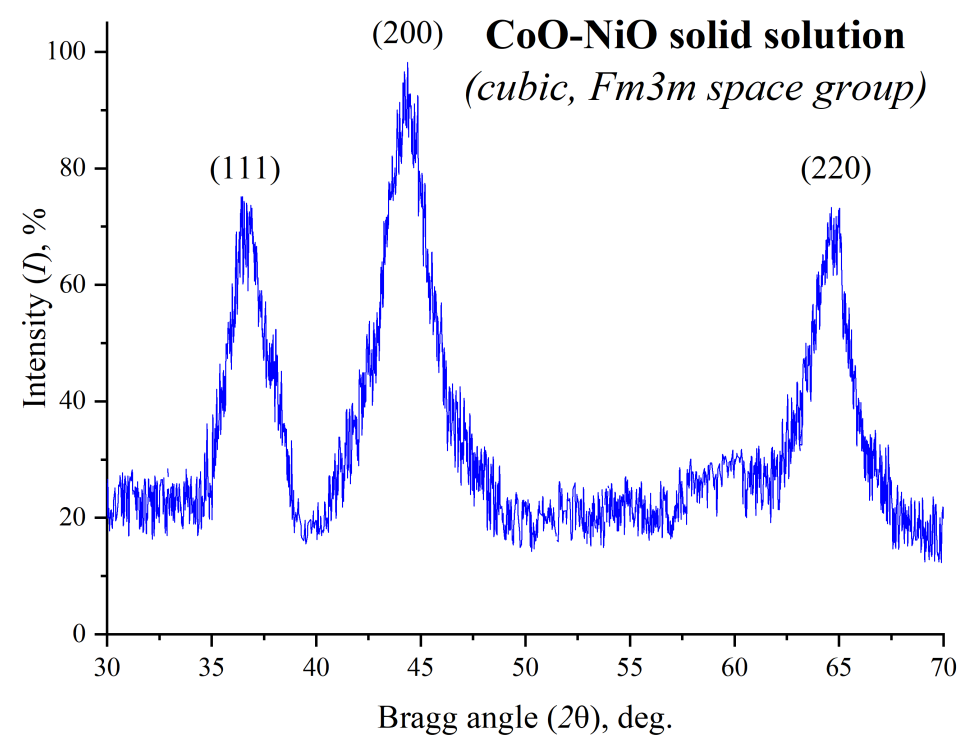

FIG. 1. XRD pattern of the synthesized nanocrystals of $\mathrm{CoO}-\mathrm{NiO}$ solid solution

The X-ray diffractogram shows three intense diffuse reflections at $36.8^{\circ}, 44.3^{\circ}$, and $64.6^{\circ}$ Bragg angles, which correspond to the crystallographic directions of (111), (200) and (220) into the cubic structure of cobalt (II) / nickel (II) oxide (space group $\mathrm{Fm} 3 \mathrm{~m}$, structural type of $\mathrm{NaCl}$ ). The X-ray diffraction lines are strongly broadened, which indicates a small crystallite size - the calculation of the average size of the coherent scattering regions, according to the Scherrer formula, gives a $3-5 \mathrm{~nm}$ value depending on the chosen crystallographic direction. There is no noticeable difference in the broadening of diffraction lines for various reflections, which indicates that the morphology of the obtained nanocrystals is close to isometric. Due to the significant broadening of the X-ray diffraction lines, an exact determination of the cubic unit cell parameter is impossible; the estimated value of the parameter $a=b=c$, determined by the Rietveld method, is 4.045(5) $\AA$. In this case, the observed shift of the X-ray diffraction lines toward large angles is slightly higher than might be expected for the $\mathrm{CoO}-\mathrm{NiO}$ solid solution, which indicates a high defectiveness of the obtained nanocrystals and the presence of a large number of vacancies in their structure. Thus, 
according to the results of X-ray diffractometry, it was found that the obtained substance is a single-phase isometric nanocrystals of a cubic solid solution of $\mathrm{CoO}-\mathrm{NiO}$, which are weakly crystallized and characterized by an imperfect structure.

SEM images (Fig. 2) also show that obtained nanocomposite of $\mathrm{CoO}-\mathrm{NiO}$ consists of ultrafine isometric crystallites - there is no noticeable anisotropy in the morphology of individual nanocrystals. Thus obtained electrode material is a film several microns thick, which consists of ultrafine nanocrystals mentioned above. The EDX analysis shows that $\mathrm{Ni} / \mathrm{Co}$ ratio in synthesized nanocrystals is equal to $45.4 \% / 54.6 \%$, so main components $(\mathrm{CoO}$ and $\mathrm{NiO})$ are in solid solution in an almost equal molar ratio.
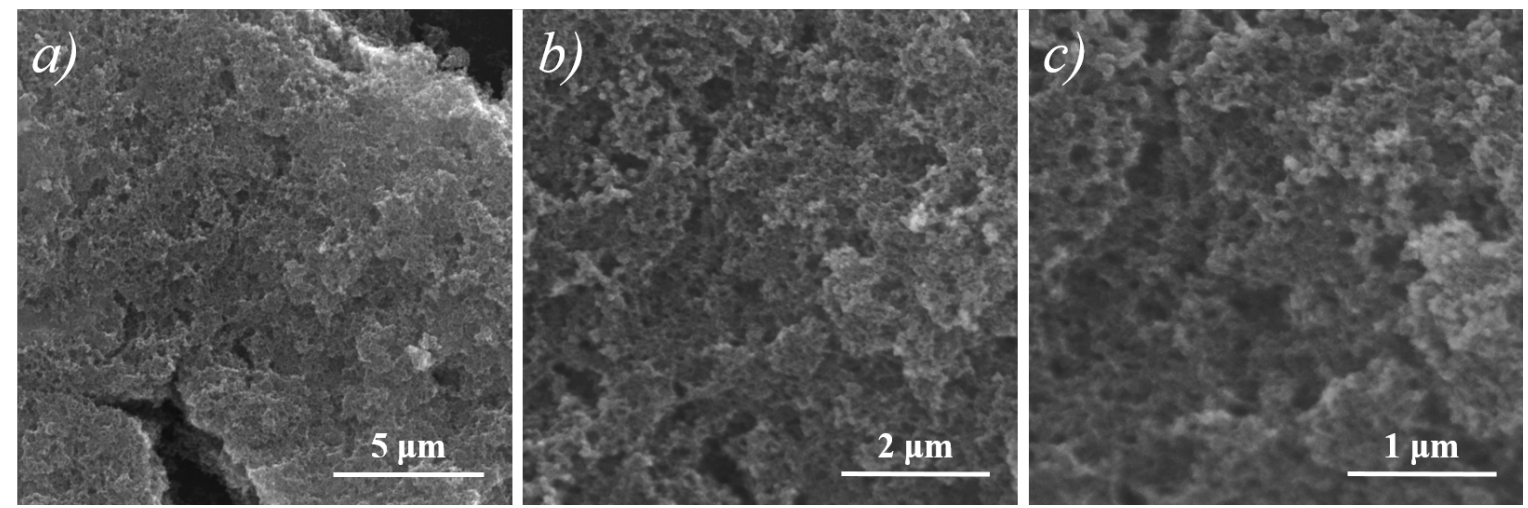

FIG. 2. SEM images of the synthesized nanocrystals of $\mathrm{CoO}-\mathrm{NiO}$ solid solution at various magnifications $(a-c)$

The electrocatalytic properties of the $\mathrm{CoO}-\mathrm{NiO}$ solid solution in the form of thin film on the nickel substrate, as an electrode for hydrogen evolution reaction, were studied by linear voltammetry methods at a constant potential sweep speed and by chronoamperometry. The voltammetry results are presented in Fig. 3. The overpotential value for pure $\mathrm{CoO}$, pure $\mathrm{NiO}$ and $\mathrm{CoO}-\mathrm{NiO}$ solid solution samples was determined and it reaches, respectively, $-277,-233$, and $-240 \mathrm{mV}$ at a current density of $10 \mathrm{~mA} / \mathrm{cm}^{2}$. These results indicate that the absolute value of overpotential for pure nickel oxide $(-233 \mathrm{mV})$ is significantly lower than for pure cobalt oxide $(-277 \mathrm{mV})$. But when considering a CoO-NiO solid solution, the absolute value of the overpotential increases slightly (to $-240 \mathrm{mV}$ ) and is closer to pure nickel oxide $(-233 \mathrm{mV})$, so the $\mathrm{CoO}-\mathrm{NiO}$ solid solution still seems to be a promising electrocatalyst.

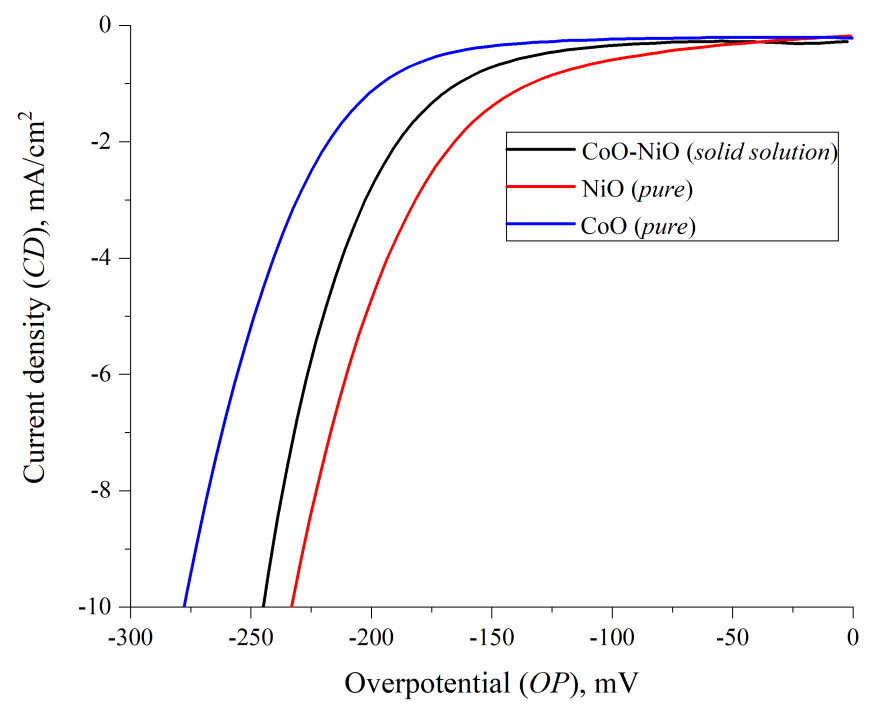

FIG. 3. Polarization curves of $\mathrm{CoO}-\mathrm{NiO}$ solid solution, and pure $\mathrm{NiO}$ and $\mathrm{CoO}$ 
The Tafel slope was also calculated (Fig. 4) from the measured current-voltage curves. It is an important microkinetic characteristic of the catalyst, which shows its efficiency over a wide range of overpotentials. The Tafel slope for $\mathrm{CoO}-\mathrm{NiO}$ solid solution, pure $\mathrm{NiO}$, and $\mathrm{CoO}$ samples was 78, 94, and $76 \mathrm{mV} / \mathrm{dec}$, respectively. Thus, the Tafel slope for the CoO-NiO solid solution $(78 \mathrm{mV} / \mathrm{dec})$ is low and very close to that for pure cobalt oxide $(76 \mathrm{mV} / \mathrm{dec})$, which characterizes the synthesized material as stable and effective for electrodes working in a wide range of overpotential values. The Tafel slope for pure nickel oxide $(94 \mathrm{mV} / \mathrm{dec})$ is much higher in comparison with the substances considered and indicates its low functional prospects as a material base for electrocatalytic hydrogen evolution.

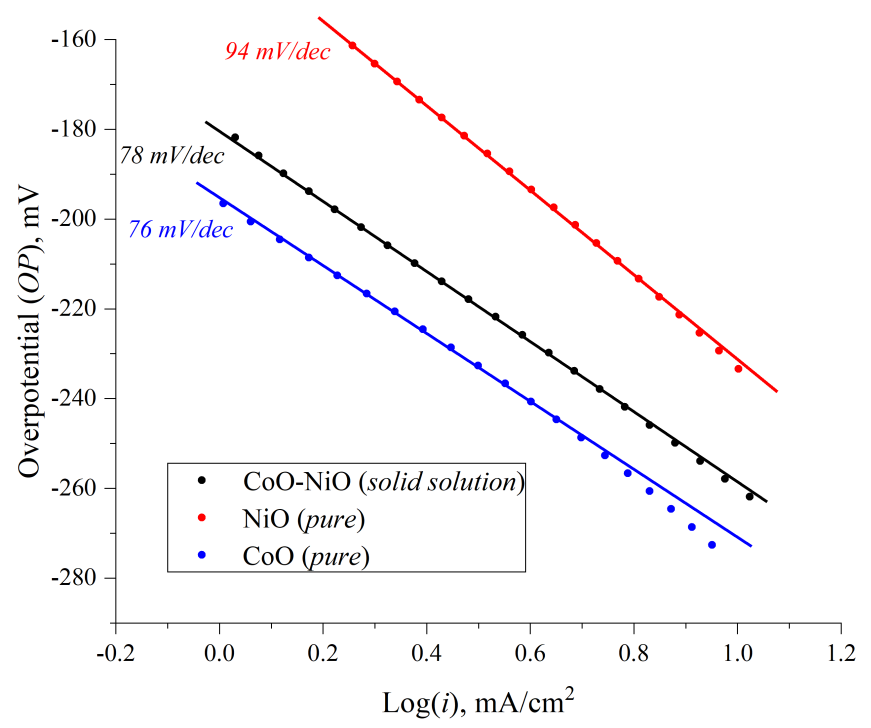

FIG. 4. The Tafel slope of $\mathrm{CoO}-\mathrm{NiO}$ solid solution, and pure $\mathrm{NiO}$ and $\mathrm{CoO}$

For $\mathrm{CoO}-\mathrm{NiO}$ solid solution and pure $\mathrm{NiO}$ and $\mathrm{CoO}$ samples, cyclic stability was measured after 100 chargedischarge cycles (Fig. 5).

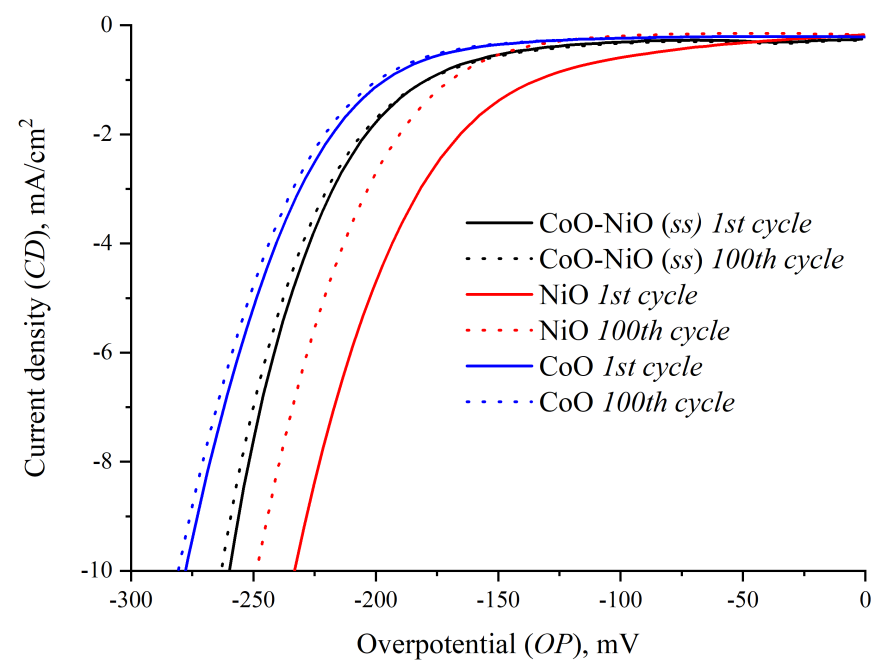

FIG. 5. Cyclic stability of $\mathrm{CoO}-\mathrm{NiO}$ solid solution, and pure $\mathrm{NiO}$ and $\mathrm{CoO}$ after 100 chargedischarge cycles

As one can see, the cyclic stability of the $\mathrm{CoO}-\mathrm{NiO}$ solid solution is at the level of pure $\mathrm{CoO}$ and much better than for pure $\mathrm{NiO}$ : the electrode degradation for both $\mathrm{CoO}-\mathrm{NiO}$ and $\mathrm{CoO}$ is only $3 \mathrm{mV}$, while for pure nickel oxide, it is higher than $15 \mathrm{mV}$. Thus, the inclusion of cobalt into the composition of nickel oxide just slightly increases the overpotential of hydrogen evolution for this catalyst, but it noticeably decreases the Tafel slope as compared with pure nickel oxide, which promotes their best microkinetic characteristics as well as decrease electrode degradation after 100 cycles of cyclic voltammetry. 


\section{Conclusion}

Nanocrystalline $\mathrm{CoO}-\mathrm{NiO}$ solid solution was synthesized by successive ionic layer deposition. XRD and SEM analysis show that the sample consists of $3-5 \mathrm{~nm}$ isometric crystallites. EDX investigation confirmed the Ni/Co ratio equal to $45.4 \% / 54.6 \%$. Electrochemical investigation of the $\mathrm{CoO}-\mathrm{NiO}-$ based electrode shows overpotential values of $-240 \mathrm{mV}$ at a current density of $10 \mathrm{~mA} / \mathrm{cm}^{2}$ and Tafel slope values of $78 \mathrm{mV} / \mathrm{dec}$ for hydrogen evolution from water-ethanol solution ( $10 \%$ vol.). And finally, it was shown that synthesized $\mathrm{CoO}-\mathrm{NiO}$ solid solution is much more stable, then pure $\mathrm{NiO}$ in cyclic voltammetry ( $3 \mathrm{mV}$ vs $15 \mathrm{mV}$ electrode degradation after 100 cycles). Thus, nanocrystalline $\mathrm{CoO}-\mathrm{NiO}$ solid solution synthesized by the SILD method could be used as an effective and stable electrode material for hydrogen production via electrocatalytic reforming.

\section{References}

[1] Lefevre M., Proietti E., Jaouen F., Dodelet J.P. Iron-based catalysts with improved oxygen reduction activity in polymer electrolyte fuel cells. Science, 2009, 324, P. 71-74.

[2] Joya K.S., Joya Y.F., Ocakoglu K., van de Krol R. Water-splitting catalysis and solar fuel devices: artificial leaves on the move. Angew. Chem., 2013, 52, 10426.

[3] Adeniyi A.G., Ighalo J.O. A review of steam reforming of glycerol. Chemical Papers, 2019, 73, P. $2619-2635$.

[4] Iulianelli A., Liguori S., Wilcox J., Basile A. Advances on methane steam reforming to produce hydrogen through membrane reactors technology: A review. Catalysis Reviews, 2016, 58, P. 1-35.

[5] Mishra P., Singh L., et al. NiO and CoO nanoparticles mediated biological hydrogen production: Effect of Ni/Co oxide NPs-ratio. Bioresource Technology Reports, 2019, 5, P. 364-368.

[6] Juodkazis K., Juodkazyte J., et al. Photoelectrolysis of water: Solar hydrogen-achievements and perspectives. Optic Express, $2010,18,147$.

[7] Jia J., Seitz L.C., et al. Solar water splitting by photovoltaic-electrolysis with a solar-to-hydrogen efficiency over $30 \%$. Nature Communications, 2016, 7, 13237.

[8] Rashid M., Al Mesfer M.K., Naseem H., Danish M. Hydrogen production by water electrolysis: a review of alkaline water electrolysis, PEM water electrolysis and high temperature water electrolysis. IJEAT, 2015, 4, 2249-8958.

[9] Ogawa T., Takeuchi M., Kajikawa Y. Analysis of trends and emerging technologies in water electrolysis research based on a computational method: a comparison with fuel cell research. Sustainability, 2018, 10, 478.

[10] Kodintsev I.A., Martinson K.D., Lobinsky A.A., Popkov V.I. Successive ionic layer deposition of $\mathrm{Co}-\mathrm{doped} \mathrm{Cu}(\mathrm{OH})_{2}$ nanorods as electrode material for electrocatalytic reforming of ethanol. Nanosystems: Physics, Chemistry, Mathematics, 2019 , 10 (5), P. $573-578$.

[11] Dmitriev D.S., Popkov V.I. Layer by layer synthesis of zinc-iron layered hydroxy sulfate for electrocatalytic hydrogen evolution from ethanol in alkali media. Nanosystems: Physics, Chemistry, Mathematics, 2019, 10 (4), P. 480-487.

[12] Wu. G., Zelenay P. Nanostructured nonprecious metal catalysts for oxygen reduction reaction. Acc. Chem. Res., 2013, 46, 1878.

[13] Staszak-Jirkovsky J., Malliakas C.D., et al. Design of active and stable Co-Mo-S $\mathrm{S}_{x}$ chalcogens as pH-universal catalysts for the hydrogen evolution reaction. Nat. Mater, 2016, 15, P. 197-204.

[14] Yuan J., Wu J., et al. Facile synthesis of single crystal vanadium disulfide nanosheets by chemical vapor deposition for efficient hydrogen evolution reaction. Adv. Mater, 2015, 27, P. 5605-5609.

[15] Popczun E.J., Read C.G., et al. Highly active electrocatalysis of the hydrogen evolution reaction by cobalt phosphide nanoparticles. Angew. Chem., 2014, 53, P. 5427-5430.

[16] Xu Y., Wu R., et al. Anion-exchange synthesis of nanoporous FeP nanosheets as electrocatalysts for hydrogen evolution reaction. Chem. Commun., 2013, 49, P. 6656-6658.

[17] Kozejova M., Latyshev V., et al. Evaluation of hydrogen evolution reaction activity of molybdenum nitride thin films on their nitrogen content. Electrochim. Acta, 2019, 315, P. 9-16.

[18] Chebanenko M.I., Zakharova N.V., Lobinsky A.A., Popkov V.I. Ultrasonic-assisted exfoliation of graphitic carbon nitride and its electrocatalytic performance in process of ethanol reforming. Semiconductors, 2019, 53 (16), P. 28-33.

[19] Guo S., Zhang S., Wu L., Sun S. Co/CoO nanoparticles assembled on graphene for electrochemical reduction of oxygen. Angew. Chem. Int. Ed. Engl., 2012, 51, P. 11770-11773.

[20] Xu Y.-F., Gao M.-R., et al. Nickel/nickel(II) oxide nanoparticles anchored onto cobalt(IV) diselenide nanobelts for the electrochemical production of hydrogen. Angew. Chem., 2013, 52, P. 8546-8550.

[21] Danilovic N., Subbaraman R., et al. Enhancing the alkaline hydrogen evolution reaction activity through the bifunctionality of Ni(OH) ${ }_{2} / \mathrm{metal}$ catalysts. Angew. Chem., 2012, 51, P. 12495-12498.

[22] Lobinsky A.A., Tolstoy V.P., Gulina L.B. A novel oxidation-reduction route for successive ionic layer deposition of $\mathrm{NiO}_{1+x} \cdot n \mathrm{H}_{2} \mathrm{O}$ nanolayers and their capacitive performance. Mater. Res. Bull., 2016, 76, P. 229-234.

[23] Lobinsky A.A., Tolstoy V.P. Red-ox reactions in aqueous solutions of $\mathrm{Co}(\mathrm{OAc})_{2}$ and $\mathrm{K}_{2} \mathrm{~S}_{2} \mathrm{O}_{8}$ and synthesis of CoOOH nanolayers by the SILD method. Nanosystems: Phys. Chem. Math., 2015, 6, P. 843-849.

[24] Tolstoy V.P. Successive ionic layer deposition. The use in nanotechnology. Russ. Chem. Rev., 2006, 75, 161.

[25] Popkov V.I., Tolstoy V.P. Peroxide route to the synthesis of ultrafine $\mathrm{CeO}_{2}-\mathrm{Fe}_{2} \mathrm{O}_{3}$ nanocomposite via successive ionic layer deposition. Heliyon, 2019, 5 (3), e01443.

[26] Popkov V.I., Tolstoy V.P., Omarov S.O., Nevedomskiy V.N. Enhancement of acidic-basic properties of silica by modification with CeO ${ }_{2}-$ $\mathrm{Fe}_{2} \mathrm{O}_{3}$ nanoparticles via successive ionic layer deposition. Applied Surface Science, 2019, 473, P. 313-17. 